\title{
FISSILE SOLUBILITY AND MONOSODIUM TITANATE
} LOADING TESTS (U)

by D.T. Hobbs

Westinghouse Savannah River Company

Savannah River Site

Aiken, South Carolina 29808

Other Authors:

This paper was prepared in connection with work done under Contract No. DE-AC09-89SR18035 with the U.S. Department of Energy. By acceptance of this paper, the publisher and/or recipient acknowledges the U.S. Government's right to retain a nonexclusive, royalty-free license in and to any copyright covering this paper, along with the right to reproduce and to authorize others to reproduce all or part of the copyrighted paper. 


\section{DISCLAIMER}

This report was prepared as an account of work sponsored by an agency of the United States Government. Neither the United States Government nor any agency thereof, nor any of their employees, makes any warranty, express or implied, or assumes any legal liability or responsibility for the accuracy, completeness, or usefulness of any information, apparatus, product, or process disclosed, or represents that its use would not infringe privately owned rights. Reference herein to any specific commercial product, process, or service by trade name, trademark, manufacturer, or otherwise does not necessarily constitute or imply its endorsement, recommendation, or favoring by the United States Government or any agency thereof. The views and opinions of authors expressed herein do not necessarily state or reflect those of the United States Government or any agency thereof.

This report has been reproduced directly from the best available copy.

Available to DOE and DOE contractors from the Office of Scientific and Technical Information, P.O. Box 62, Oak Kidge, TN 37831; prices available from (615) 576-8401, FTS 626-8401.

Available to the public from the National Technical Information Service, U.S. Department of Commerce, 5285 Port Royal Rd., Springfield, VA 22161. 
WESTINGHOUSE SAVANNAH RIVER COMPANY WSRC-RP-92-1273 SAVANNAH RIVER LABORATORY

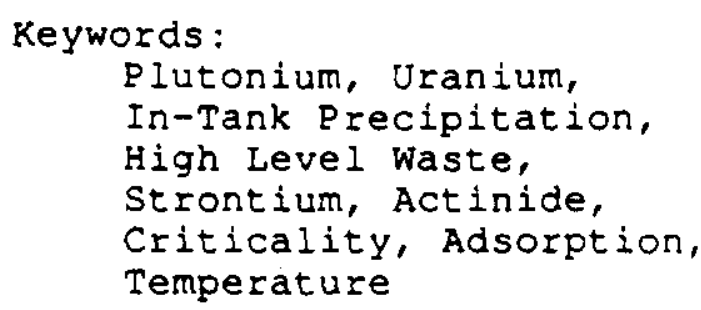

Retention time: permanent

February 12, 1993

TO: D. L. Fish, 773-A

DTH

FROM: D. T. Hobbs, 773-A and S. D. Fleischman, 773-A

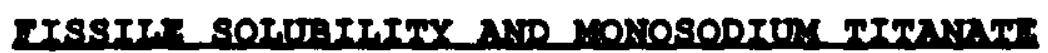

IONDTIC TH+STS (D)

\section{SUMARRY}

The solubilities of plutonium and uranium have been determined for alkaline salt solutions having compositions which bound those which will be processed in the In-Tank Precipitation (ITP) process. Loadings of plutonium and uranium onto monosodium titanate (MST) have been determined at temperatures bounding those expected to occur during ITP and using a salt solution which was determined to have the maximum solubility for uranium and plutonium. Fissile loadings increase with decreasing amounts of MST in contact with the salt solutions saturated in plutonium and uranium. At MST concentrations bounding those which are planned for the ITP process, expressions for the maximum loadings (wt. $\frac{8}{2}$ ) are determined to be $0.29-0.20 \times[M S T]$ for plutonium and 1.8 $0.29 \times$ [MST] for uranium, where [MST] is the concentration of MST in grams/liter. These expressions are valid over the range of MST concentrations from 0.05 to $0.51 \mathrm{~g} / \mathrm{L}$ and temperatures of $17^{\circ}-74^{\circ} \mathrm{C}$. These loadings are below the individual infinitely safe limits for plutonium and uranium.1-3 Additional confirmatory experiments are planned to verify the effects of temperature and multiple contacts of the MST with fresh salt solution on the fissile loadings. 


\section{INTRODUCTION}

Monosodium titanate strongly adsorbs divalent ions such as strontium in alkaline salt solutions and will be used in the ITP process to remove radio-strontium species from salt solution. Certain actinides are also reported to be adsorbed by MST. ${ }^{4}$ Previous tests determined the loadings of plutonium and uranium at a single salt solution composition which was within the expected range of compositions which will be processed in the ITP process.5 However, because of the uncertainty in the solubility of plutonium and uranium over the entire range of salt solution compositions, additional tests were recommended to determine the maximum fissile solubility. Maximum loadings of plutonium and uranium could then be determined by measuring the loadings using salt solutions having maximum plutonium and uranium solubilities.

\section{EXPERIMIATINL}

Solubility Tests

All salt solutions for the matrix solubility tests were prepared in calibrated volumetric glassware using reagent grade chemicals of the same manufacturer and lot number (see table I). A single batch of deionized, distilled water was collected and stored in large polyethylene bottles for use in all solution preparations. All solutions were filtered through a 0.45 micron nitrocellulose filter to remove any undissolved solids prior to use.

Table I. Manufacturer and Iot of Chemicals Used in Solubility reata

$\begin{array}{lll}\text { Chemical } & \text { Manufacturer } & \text { Iot: } \\ \mathrm{NaNO}_{3} & \text { Eisher } & 912637 \\ \mathrm{NaOH} & \text { EM } & 32015207 \\ \mathrm{Na}_{2} \mathrm{SO}_{4} & \text { Fisher } & 895669 \\ \mathrm{Na}_{2} \mathrm{CO}_{3} \cdot \mathrm{H}_{2} \mathrm{O} & \text { Baker } & \text { B45165 } \\ \mathrm{NaNO}_{2} & \text { Fisher } & 916644 \\ \mathrm{Al}\left(\mathrm{NO}_{3}\right)_{3} \cdot 12 \mathrm{H}_{2} \mathrm{O} & \text { Eisher } & 920145\end{array}$

For each test, a 500-mL polyethylene bottle was filled with $475 \mathrm{~mL}$ of salt solution. Each bottle was spiked with $0.25 \mathrm{~mL}$ of an enriched-uranium nitrate solution $(200 \mathrm{~g}$ U/liter, ca. 908 $\mathrm{U}-235)$ and $0.025 \mathrm{~mL}$ of a weapons-grade plutonium nitrate solution $130.7 \mathrm{~g}$ $\mathrm{Pu} / \mathrm{L}, 948 \mathrm{Pu}-239,68 \mathrm{Pu}-240)$. The bottles were stoppered and placed in a two-tier rack equipped with an air-actuated shaker. The rack was then placed into a water bath such that the bottom tier of bottles was immersed in water and the top tier was above 
the water. A layer of insulation was placed beneath the top tier of bottles to minimize heat transfer from the heated water.

During the course of the solubility testing, the position of the bottles was rotated to reduce the possibility of uncontrolled variations in the temperature within the shaker/water-bath. The order of sampling each set of 10 bottles on each tier was also varied. Prior to sampling, the air supply to the shaker was shut off overnight to allow any solids to settle.

The sampling procedure consisted of filtering a small sample of the test solution into a clean vial, and then acidifying a known quantity of the filtered solution with nitric acid. Approximately six mililiters of the test solution were drawn into a disposable plastic syringe, and then passed through a $0.45 \mu \mathrm{m}$ nitrocellulose cartridge filter into a clean bottle. Five milliliters of the filtered solution were pipetted into a glass vial containing a sufficient amount of a $1: 1$ mixture (by weight) of concentrated nitric acid and deionized, distilled water to neutralize the sample and provide a final $\mathrm{pH}$ of $\leq 1$.

Each sample was analyzed by the Analytical Development Section of the Savannah River Technology Center for uranium and plutonium content. The uranium content was determined by two different instrumental methods; (1) kinetic phosphorescence analyzer and (2) inductively coupled plasma/mass spectrometry. The plutonium content was also determined by two separate methods; (1) alpha scintillation counting and (2) inductively coupled plasma/mass spectrometry.

\section{Leading Tests}

All loading tests were conducted using synthetic salt solutions having the composition given in Table II. The salt solutions were prepared using deionized, distilled water and reagent grade chemicals. Reagent grade strontium nitrate (Mallinckrodt, Lot * KHGD) was added to each solution batch to provide a strontium ion concentration of $2 \times 10^{-8}$ molar. Excess amounts of plutonium and uranium were added to the salt solutions to exceed the solubility Iimit. The spiked solutions were stirred for a minimum of one week and then filtered through a medium porosity fritted-glass filter prior to use in the loading tests. All of the experiments were conducted with a single MST slurry sample prepared by the Boulder Sclentific Company (Lot \#265-0005), which was determined to have a strontium DF value of $242 \pm 28$ at a MST concentration of $0.5 \mathrm{~g} / \mathrm{liter}$ of salt solution.

A known quantity of salt solution was placed in a polyethylene bottle equipped with a magnetic stirring bar. Based on the desired concentration of MST for the test, a sufficient quantity of the MST slurry was weighed out and transferred to the bottle containing the salt solution. The bottle was then stoppered and mixed at $19 \pm 2^{\circ} \mathrm{C}$ for one week. For the high temperature tests, the bottle was heated to $72 \pm 2^{\circ} \mathrm{C}$ either in a water bath or a sand bath for a period of one week. 
Table II. Composition of synthotic salt solution for Loading Teat:

$\begin{array}{lc}\text { Species } & \text { cencentratien (mole/L) } \\ \text { NaOH } & 1.0 \\ \mathrm{NaNO}_{3} & 2.0 \\ \mathrm{NaNO}_{2} & 0.10 \\ \mathrm{NaAl}_{(\mathrm{OH})_{4}} & 0.33 \\ \mathrm{Na}_{2} \mathrm{SO}_{4} & 0.40 \\ \mathrm{Na}_{2} \mathrm{CO}_{3} & 0.02 \\ \mathrm{Total} \mathrm{Na} & 4.3\end{array}$

The test slurry was then filtered through a medium porosity (10-50 $\mu$ pore diameter) fritted glass funnel. The filtered salt solution was stored in a clean polyethylene bottle. The MST solids were washed with small portions of deionized, distilled water and then dissolved in approximately $20 \mathrm{~mL}$ of $1: 1 \mathrm{mixt} u \mathrm{re}$ of concentrated sulfuric acid and deionized, distilled water. The wash water was stored in a clean polyethylene bottle. The dissolved MST solids were filtered through the glass funnel, transferred to a $50-\mathrm{mI}$ volumetric flask, and diluted to the mark with deionized, distilled water.

Triplicate samples of the treated and untreated salt solutions, the wash waters, and the dissolved solids solution were then analyzed for uranium, plutonium, strontlum, and titanium content using a combination of analytical methods including alpha scintillation counting, kinetic phosphorescence, inductively coupled plasma/emission spectrometry and inductively coupled plasma/mass spectrometry.

\section{RESUTTS}

Solubility Tests

A fractional factorial experimental design ${ }^{6}$ was used to determine the maximum solubility of plutonium and uranium in alkaline salt solutions having compositions which bound those that will be treated in the ITP process. Table III shows the minimum and maximum values for the each of the parameters in the test matrix and Table IV shows the coded experimental design.

Samples from each of the test solutions were taken after $3,7,14$, 25 and 31 days and analyzed for plutonium and uranium content. Over this period no significant effect of time was observed. 

D. L. Fish
- page 5 -
WSRC-RP $-92-1273$

A plot of the plutonium and uranium concentrations for each test solution at the 31-day sampling versus the hydroxide concentration is presented in Figure 1. Each data set was analyzed to determine significant factors and interactions.

Table III. Solubility Test vatrix Perameters

$\begin{array}{cll}\text { Rarameter } & \text { Minimum } & \text { Meximum } \\ \mathrm{OB}^{-} & 0.5 \mathrm{M} & 2.0 \mathrm{M} \\ \mathrm{NO}_{2}^{-} & 0.2 \mathrm{M} & 1.0 \mathrm{M} \\ \mathrm{M}(\mathrm{OB})^{-} & 0.05 \mathrm{M} & 0.33 \mathrm{M} \\ \mathrm{NO}_{3}^{-} & 1.0 \mathrm{M} & 4.0 \mathrm{M} \\ \mathrm{CO}_{3}^{2-} & 0.02 \mathrm{M} & 0.30 \mathrm{M} \\ \text { so }_{4}^{2-} & 0.02 \mathrm{M} & 0.40 \mathrm{M} \\ \text { Temperature } & \text { ambient } & 60{ }^{\circ} \mathrm{C}\end{array}$

rable IV. Solubility Toat Experimental Dosign

$\begin{array}{crrrrrrr}\text { Ixpt } & \mathrm{OH}^{-} & \mathrm{NO}_{2}{ }^{-} & \mathrm{Al}(\mathrm{OH})_{4}^{-} & \mathrm{NO}_{3}{ }^{-} & \mathrm{CO}_{3}{ }^{2-} & \mathrm{SO}_{4}{ }^{2-} & \mathrm{Tamp}^{-} \\ 1 & 1 & 1 & 1 & 1 & 1 & 1 & 1 \\ 2 & -1 & 1 & 1 & 1 & -1 & 1 & -1 \\ 3 & 1 & -1 & 1 & 1 & -1 & -1 & 1 \\ 4 & -1 & -1 & 1 & 1 & 1 & -1 & -1 \\ 5 & 1 & 1 & -1 & 1 & -1 & -1 & -1 \\ 6 & -1 & 1 & -1 & 1 & 1 & -1 & 1 \\ 7 & 1 & -1 & -1 & 1 & 1 & 1 & -1 \\ 8 & -1 & -1 & -1 & 1 & -1 & 1 & 1 \\ 9 & 1 & 1 & 1 & -1 & 1 & -1 & -1 \\ 10 & -1 & 1 & 1 & -1 & -1 & -1 & 1 \\ 11 & 1 & -1 & 1 & -1 & -1 & 1 & -1 \\ 12 & -1 & -1 & 1 & -1 & 1 & 1 & 1 \\ 13 & 1 & 1 & -1 & -1 & -1 & 1 & 1 \\ 14 & -1 & 1 & -1 & -1 & 1 & 1 & -1 \\ 15 & 1 & -1 & -1 & -1 & 1 & -1 & 1 \\ 16 & -1 & -1 & -1 & -1 & -1 & -1 & -1 \\ 17 & 0 & 0 & 0 & 0 & 0 & 0 & -1 \\ 18 & 0 & 0 & 0 & 0 & 0 & 0 & -1 \\ 19 & 0 & 0 & 0 & 0 & 0 & 0 & 1 \\ 20 & 0 & 0 & 0 & 0 & 0 & 0 & 1\end{array}$


Over the range of solution compositions tested, the plutonium solubility ranged from 0.01 to $1.0 \mathrm{mg} / \mathrm{L}$. From Figure 1, the plutonium solubility tends to increase with increasing hydroxide concentration. Although there is over two orders of magnitude change in the plutonium solubilities, there were no statistically significant factors or interactions affecting the plutonium solubility up to and including 31 days of contact over the range of variables studied in this test.?

Analysis of the uranium solubility data revealed one factor and two interactions as being statistically significant.? The statistically significant factor is the hydroxide concentration. An increase in the hydroxide concentration increases the uranium solubility. The two significant interactions are (1) hydroxide and nitrate and (2) hydroxide and carbonate. An increase in the interactions (i.e. an increase in the product of the two concentrations), hydroxide and nitrate and hydroxide and carbonate, decrease the uranium solubility. Figure 1. Plutonium and Oranium Concentrations versus
Bydroxide Concentration

(Matrix Tests 31 days)

\section{Concontration} (mgll)

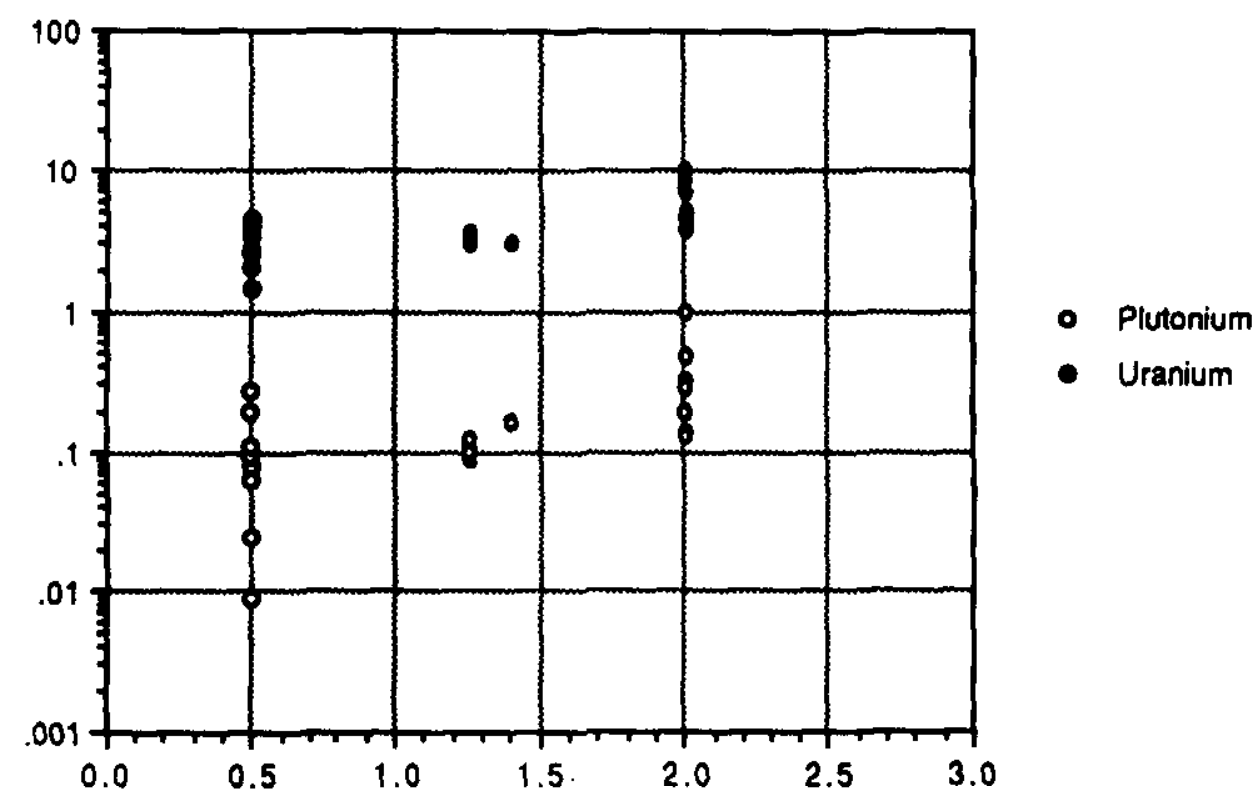

Hydroxide Concentration (molel L) 
D. L. Eish

- page 7 -

WSRC-RP $-92-1273$

Continuous Loadings Tests

From the 31-day solubility test results, a single salt solution composition was selected for the loading tests. The salt composition of this solution is given in Table II. Reagent grade strontium mitrate was added to each batch at a concentration of $2 \times 10^{-8}$ molar so that the fissile loadings would reflect competition among plutonium, uranium and strontium for sites on the MST.

Originally, it was planned to conduct fissile loading tests in a continuous manner using a glass column packed with the MST much like that used to conduct ion-exchange loading tests. This flow arrangement provides a continuous feed of salt solution saturated with uranium and plutonium to the MST so that the MST always sees the maximum chemical potential for uranium and plutonium.

Analysis of the solution before and after contact with the MST would then allow determination of when the MST was no longer removing uranium and plutonium from solution. At that point the tests would be stopped and the MST solids analyzed to determine maximum possible loadings of uranium and plutonium.

In preliminary experiments to determine bed depths at different column diameters, it was found that flowrates were significantly below that necessary to complete the tests in support of the ITP schedule. Higher flowrates were possible at higher pressures. However, due to the presence of alpha-emitting materials (ca. $10^{8}$ dpm of Pu-239) in the solution and the unknown effects of pressure, it was decided to modify the experiment so that the tests could be conducted at low pressure.

Excellent flowrates were achieved by depositing a thin layer of the MST solids on a sintered metal filter having a nominal pore size of 0.5 microns. To prevent the accidental transfer of uranium and plutonium solids from the saturated salt solution, a 60-micron sintered-metal prefilter was placed fust prior to the MST-coated filter. Two continuous tests were started, one at ambient temperature and one at $75^{\circ} \mathrm{C}$.

After 2.6 liters of salt solution had been passed in the ambient temperature test and shortly after adding fresh salt solution to the feed reservoir, the flowrate dropped very quickly. During the addition of the fresh salt solution, the undissolved uranium and plutonium solids were intentionally suspended to ensure good mixing. The test was stopped and the coated filter inspected. The inspection revealed yellow-brown solids in addition to the white MST solids at the end closest to the entrance into the filter housing. Analysis of the solids indicated that the yellow-brown solids were primarily uranium. Apparently when the fresh salt solution was added to the reservoir, sufficient undissolved solids were passed through the 60 micron prefilter into the MST-coated filter and collected on the MST solids. 
In the high temperature test, a total of 18.93 liters of salt solution was passed through the coated filter before the experiment was stopped. Yellow-brown solids were also observed in this experiment. Because of the questionable data quality of the continuous loading tests and the length of time that is required to conduct this type of test, it was decided to conduct additional batch lc iding tests.

\section{Single-Contact Batch Leading Tests}

Single-contact batch loading tests were carried out at three different MST concentrations and two different temperatures, $19 \pm$ $2^{\circ} \mathrm{C}$ and $72 \pm 2^{\circ} \mathrm{C}$ using a salt solution containing strontium and saturated with plutonium and uranium. The loading data were plotted versus the MST concentration and then regressed to provide an expression for the wt. $f$ loading as a linear function of the MST concentration.

Duplicate tests were made at a MST concentration of $0.50 \mathrm{~g} / \mathrm{L}$ at both temperatures to estimate the experimental error of the test method. This concentration was selected since it would represent the lowest concentration of plutonium and uranium per unit mass of MST, and therefore, presumably the greater source of error. During experiments 9 and 10 , the test slurries were inadvertenty allowed to cool to room temperature. The slurries were reheated to the loading temperature overnight, and then filtered to separate the MST solids from the salt solution.

Two methods were used to determine the loadings of plutonium and uranium on the MST solids. In method $A$, the uranium data from the kinetic phosphorescence analyses, the plutonium data from the ICP/MS analyses, and the strontium and titanium data from the ICP/ES analyses were utilized to determine the loadings. In Method B, the loadings were determined using the analytical results solely from the ICP/MS analyses.

The plutonium and uranium loadings for each test are given in Tables $V$ and VI. Figure 2 presents a graph of the weight percent loadings for plutonium and uranium as a function of the MST concentration at $19^{\circ} \mathrm{C}$. Also included are the linear regression equations for the $19^{\circ} \mathrm{C}$ data sets for loadings determined by both method $A$ and method $B$. Over the range of MST concentrations tested, $0.0513-0.506 \mathrm{~g} / \mathrm{L}$, the average plutonium loading changed by a factor of about five 10.032-0.15 wt. 8 , but the average uranium loading changed by only about $23 \%(0.64-0.79$ wt. 8$)$. 
D. L. Fish

WSRC-RP - 92-1273

Table V. Plutonium Loading Test Results

\begin{tabular}{|c|c|c|c|c|}
\hline Test & $\begin{array}{l}\{M S T\} \\
(g / L]\end{array}$ & $\begin{array}{c}\text { Temperature } \\
\left({ }^{\circ} \mathrm{C}\right) \\
\end{array}$ & Method_A & $\begin{array}{l}\text { Pu Method B } \\
\text { Methen }\end{array}$ \\
\hline 5 & 0.503 & $19 \pm 2$ & $0.028 \pm 0.0020$ & $0.033 \pm 0.0015$ \\
\hline 6 & 0.499 & $19 \pm 2$ & $0.030 \pm 0.0026$ & $0.036 \pm 0.0038$ \\
\hline 7 & 0.151 & $19 \pm 2$ & $0.064 \pm 0.0061$ & $0.069 \pm 0.007$ \\
\hline 8 & 0.0513 & $19 \pm 2$ & $0.14 \pm 0.0044$ & \pm 0.0050 \\
\hline 2 & 0.102 & $72 \pm 2$ & $0.16 \pm 0.0062$ & - \\
\hline 9 & 0.506 & $72 \pm 2$ & $0.024 \pm 0.0013$ & $0.028 \pm 0.0017$ \\
\hline 10 & 0.505 & $72 \pm 2$ & $0.023 \pm 0.0013$ & $0.029 \pm 0.0015$ \\
\hline
\end{tabular}

Method A: Pu determined by ICP/MS, U determined by kinetic phosphorescence, $S r$ and Ti determined by ICP/ES.

Method B: Pu, U, Sr and Ti determined by ICP/MS.

Table VI. Uranium Loading Tast Rasults

\begin{tabular}{|c|c|c|c|c|}
\hline Test \# & [MST] & Temperature & Wt & U \\
\hline & $10 / L 1$ & $\left({ }^{\circ} \mathrm{C}\right)$ & Method_A & Methed $B$ \\
\hline 5 & 0.503 & $19 \pm 2$ & $0.57 \pm 0.045$ & $0.69 \pm 0.031$ \\
\hline 6 & 0.499 & $19 \pm 2$ & $0.58 \pm 0.053$ & $0.71 \pm 0.079$ \\
\hline 7 & 0.151 & $19 \pm 2$ & $0.68 \pm 0.068$ & $0.77 \pm 0.085$ \\
\hline 8 & 0.0513 & $19 \pm 2$ & $0.73 \pm 0.023$ & $0.85 \pm 0.028$ \\
\hline 2 & 0.102 & $72 \pm 2$ & $0.50 \pm 0.019$ & - \\
\hline 9 & 0.506 & $72 \pm 2$ & $0.56 \pm 0.024$ & $0.73 \pm 0.044$ \\
\hline 10 & 0.505 & $72 \pm 2$ & $0.52 \pm 0.029$ & $0.70 \pm 0.030$ \\
\hline
\end{tabular}

Method A: Pu determined by ICP/MS, U determined by kinetic phosphorescence, $S T$ and $\mathrm{Ti}$ determined by $\mathrm{ICP} / \mathrm{ES}$.

Method B: Pu, U, Sx and Ti determined by ICP/MS. 
Figure 2. Plutonium and Uranium Loadings at $19^{\circ} \mathrm{C}$ as a

Iunction of the MST Concentration

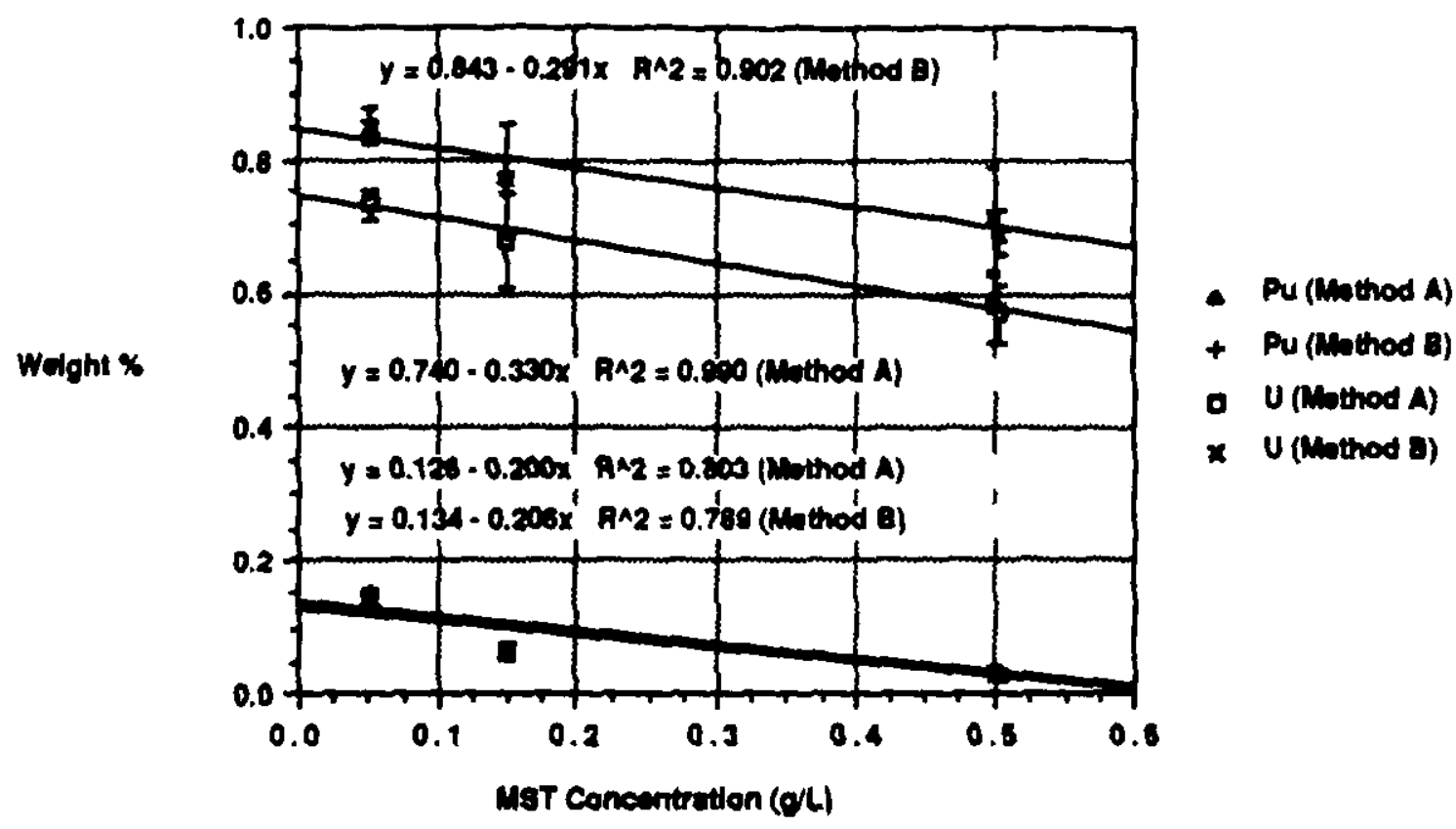

rigure 3. Plutonium and Urantum Loadings at $19^{\circ} \mathrm{C}$ and $72^{\circ} \mathrm{C}$ a a runction of the MST Concentration (Nothod A)

Woight $\%$

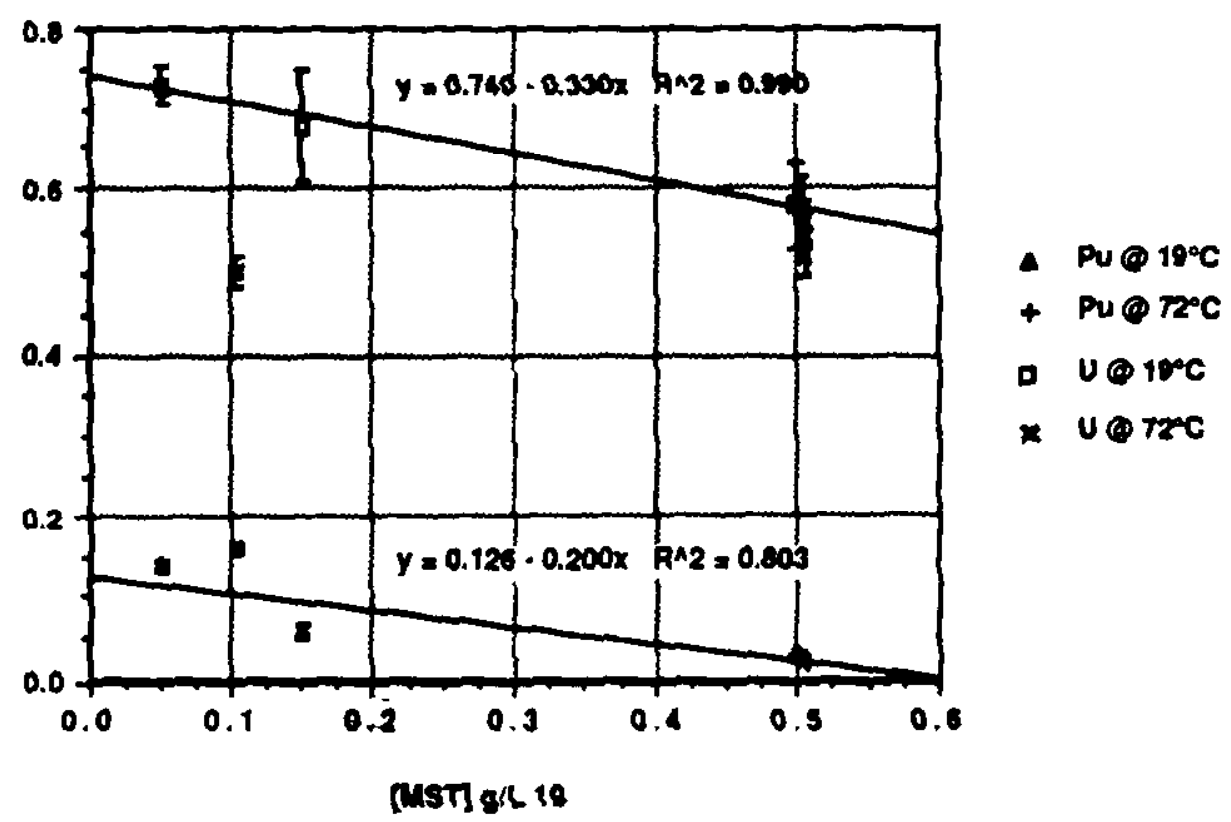




\section{Rlutenium and Uranium Mass Balances}

The mass balances for plutonium and uranium in each test are given in Table VII for plutonium and Table VIII for uranium. The mass balance for uranium was excellent for all of the experiments. At the 998 confidence level, all of the uranium initially present could be accounted for based on the sum of uranium determined in the treated salt solution, wash waters, and the dissolved MST solids solution. The mass balance for plutonium was not quite as good as that found for uranium. This is probably due to the lower concentrations of plutonium relative to uranium, which result in an overall increase in the sampling and analytical uncertainty.

With the exception of test $\# 2$, the untreated salt solution, the treated salt solution, the wash water, and the dissolved solids were all analyzed for plutonium and uranium content to determine a mass balance for each loading test. In test \#2, the untreated salt solution was not analyzed prior to treatment with MST. For calculation of the initial amounts of plutonium and uranium in this experiment, the average concentrations for the untreated salt solutions used in experiments $\# 5-\$ 10$ were used.

\section{Table VII. Plutonium Masa Balance}

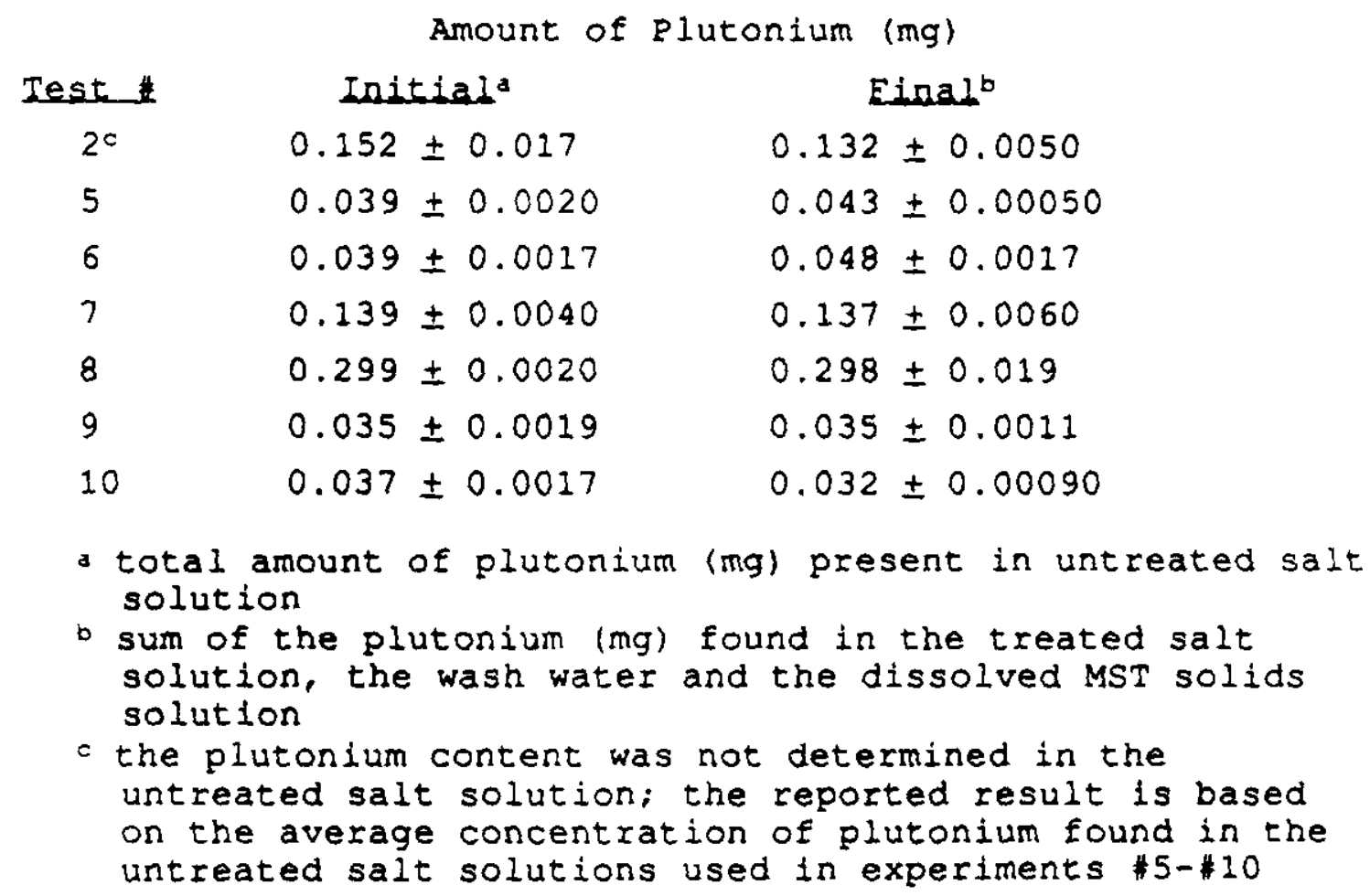


D. L. Fish

- page 12 -

WSRC-RP $-92-1273$

Table VIII. Oranium Mass Balance

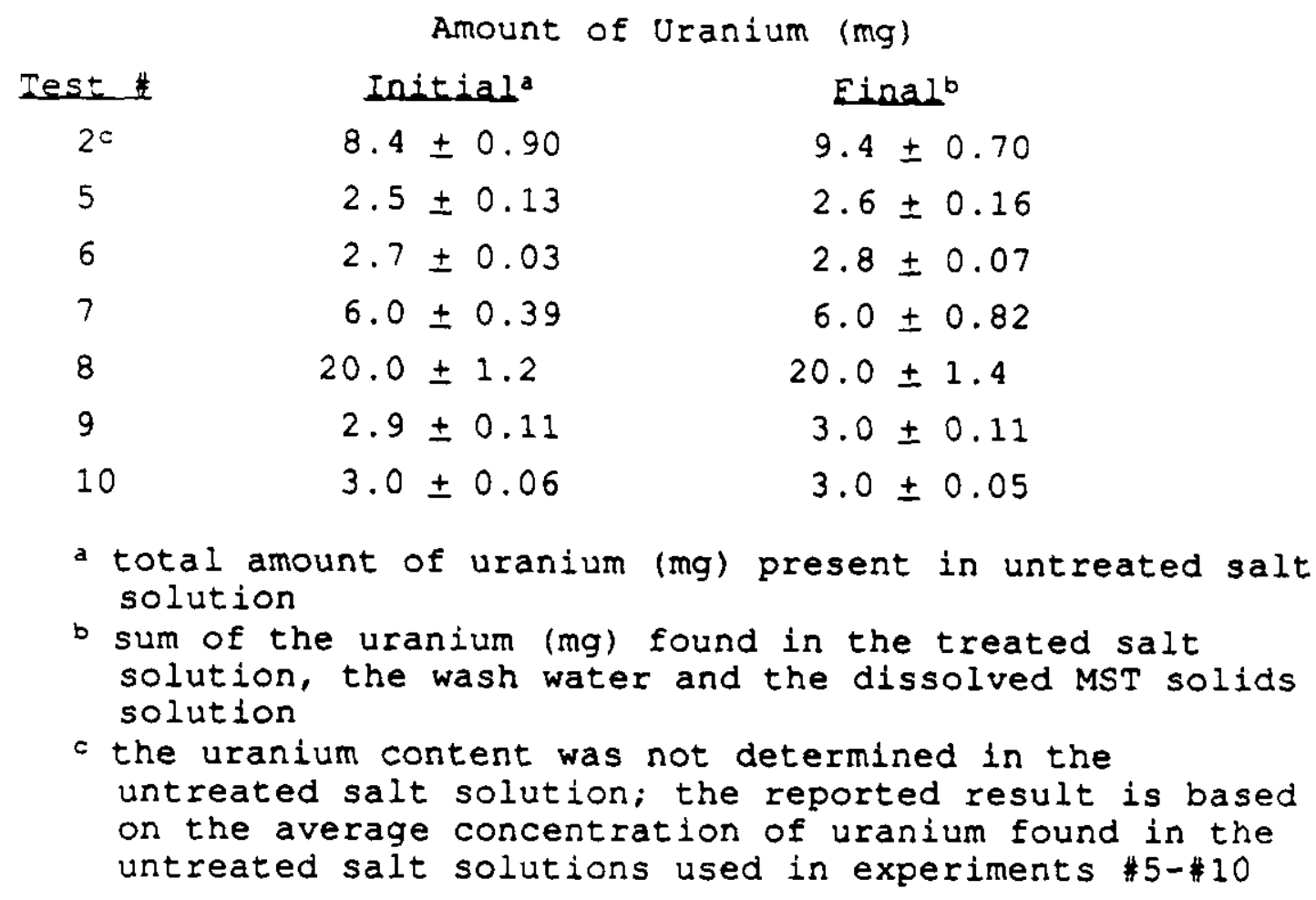

Maximum Uranium Ioading

From the single-contact batch loading results, the maximum loading of uranium over the range of MST concentrations tested is determined to be 1.1 wt. 8 . This value was determined by taking the maximum uranium loading value at $0.05 \mathrm{~g} / \mathrm{L}$ of MST $(0.85 \mathrm{wt}$. 8 ), and multiplying by a factor of 1.33, which is three times the relative error measured for the uranium loadings in duplicate tests by the two analytical methods.

Maximum Rlutonium Ioadiog

For plutonium, the maximum loading is determined to be 0.28 wt. 8 . The maximum plutonium loading was determined by estimating the loading at $0.05 \mathrm{~g} / \mathrm{L}$ of $\mathrm{MST}$ at $72^{\circ} \mathrm{C}(0.21$ wt 8$)$, and multiplying by a factor of 1.33 , which is three times the relative error measured for the plutonium loadings in duplicate tests by the two analytical methods.

Fitting only the experimental loading data for the extreme MST concentrations $(0.051$ and $0.50 \mathrm{~g} / \mathrm{L})$ to a linear expression yields the following equation,

$$
y=0.15-0.25 x
$$


where $x=$ the MST concentration in $g / L$. To estimate the loading at the extreme MST concentrations, a parallel line was drawn through the $72^{\circ} \mathrm{C}$ experimental loading result measured at a MST concentration of $0.102 \mathrm{~g} / \mathrm{L}$. The equation for this line is

$$
y=0.19-0.25 x
$$

Note that the loading value determined at a MST concentration of $0.151 \mathrm{~g} / \mathrm{L}$ at $19^{\circ} \mathrm{C}$ is lower by $0.046 \mathrm{wt} . \frac{8}{8}$ than that calculated by equation 1 above. Thus, the loading values which would be determined at the extreme MST concentrations at $72^{\circ} \mathrm{C}$, may be higher. To estimate what the loading values would be at the higher temperature and at the extreme concentrations, it was assumed that these points would fall on a line parallel to that passing through the experimental value at $0.102 \mathrm{~g} / \mathrm{L}$, but displaced above this line by an amount relative to that observed for the $19^{\circ} \mathrm{C}$ experimental result determined at $0.151 \mathrm{~g} / \mathrm{L}$. Applying this correction gives a line having the form

$$
y=0.22-0.25 x
$$

Using equation 3 the plutonium loading at a MST concentration of $0.05 \mathrm{~g} / \mathrm{L}$ is determined to be 0.21 wt. at $72^{\circ} \mathrm{C}$. This result was then multiplied by a factor of 1.33 to give a maximum loading value of $0.28 \mathrm{wt}$. . The factor of 1.33 allows for the experimental uncertainty and is equal to three times the relative error measured for duplicate tests.

\section{Figure 4. Determination of Plutonium Ioading at $72^{\circ} \mathrm{C}$}

Wt $\%$ Pu

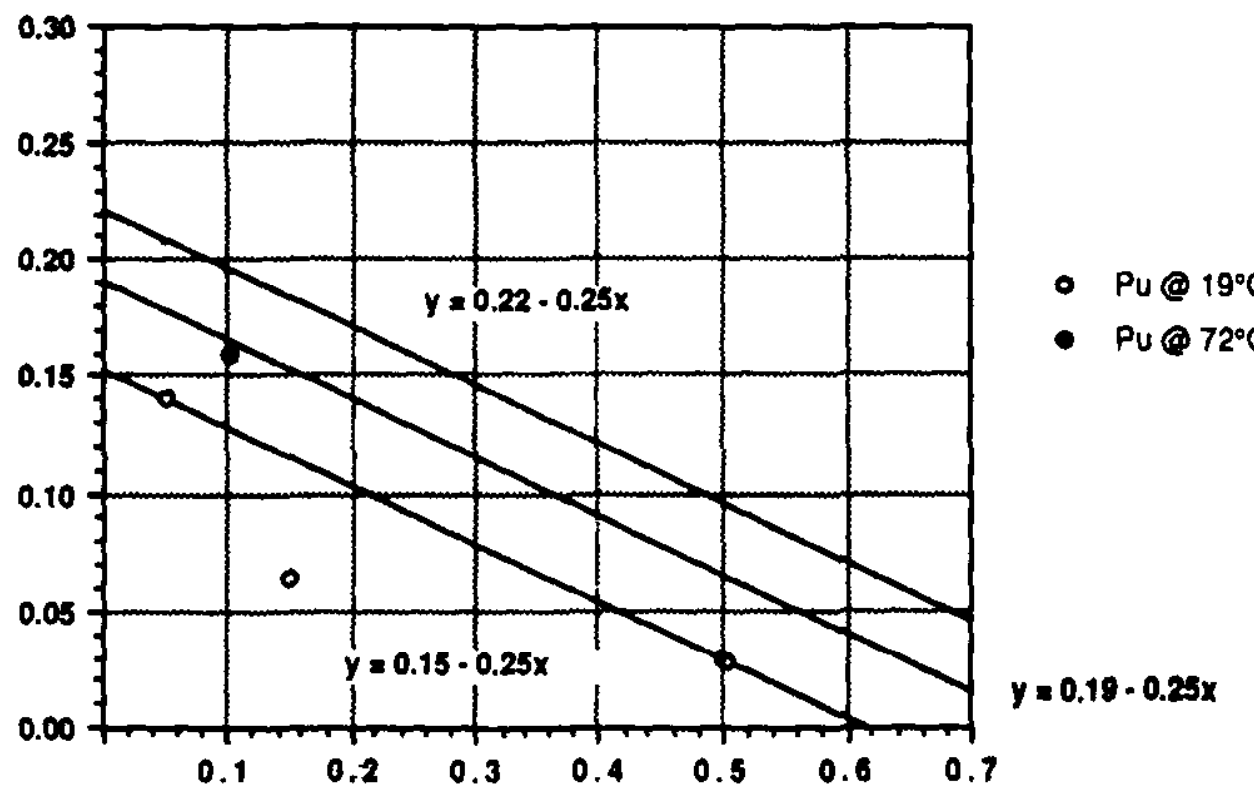

MST Concentration ( $g / L)$ 


\section{Adsorption Models}

$F$ igures 5 and 6 show the room temperature loading data plotted using terms derived for the Langmuir and Freundlich adsorption models. The Langmuir model assumes that the molecules are adsorbed on definite sites with each site having the same energy and that each site can only accommodate one molecule. The Freundich model is an empirical expresston that considers the adsorbent to be heterogeneous with an exponential distribution of sites and energies.

Both the plutonium and uranium loading data fit a Fruendlich model fairly well. The uranium loading data, but not the plutonium loading data, also fit a Langmuir model fairly well. The high temperature data for both plutonium and uranium do not fit either model well. The lack of fit of the high temperature data may be due to inadvertent cooling of the Tests $\# 9$ and 10 .

From inspection of the Freundlich adsorption graphs, the MST has a high adsorption capacity for plutonium and uranium at high equilibrium concentrations which rapidly diminishes at lower concentrations. The adsorption of plutonium diminishes more rapidly than that of urantum based on the steeper slope of the line. From the Langmuir model, a monolayer capacity of 1.3 wt. uranium was determined for this batch of MST.

\section{Figure 5a. Fit of Plutonium Ioading Data to Inngmuir Adsorption Kodel}

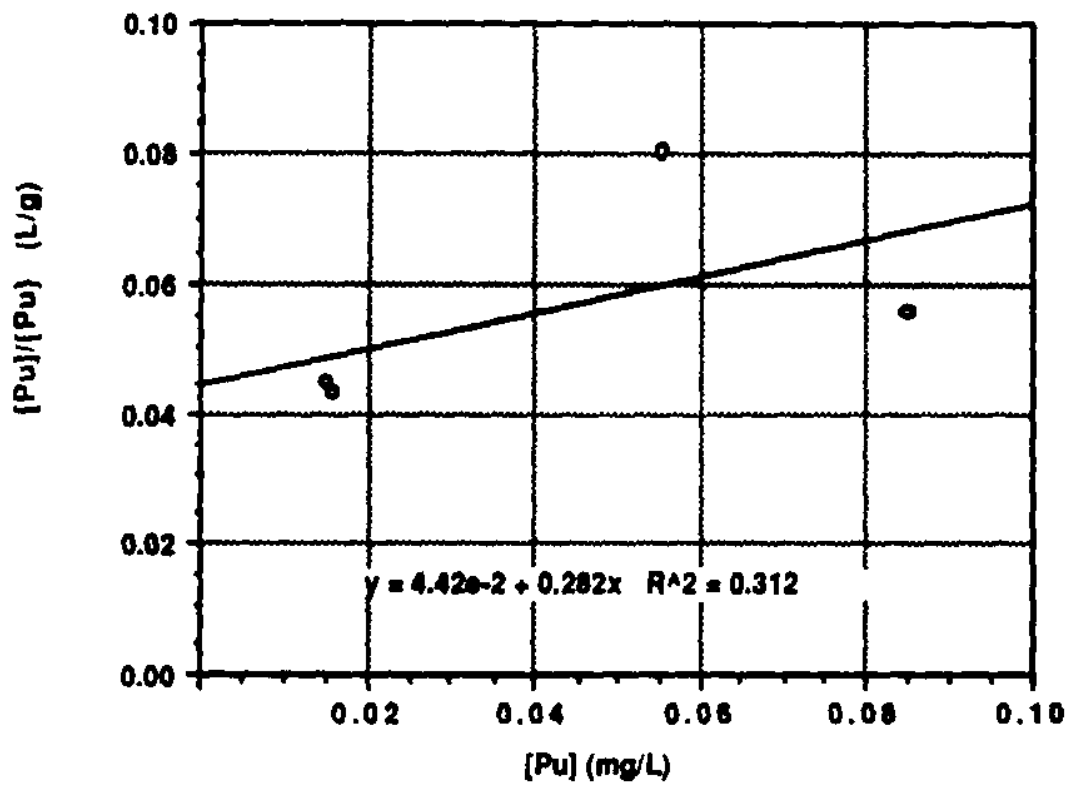

$[P u]=$ Equilibrium Solution Pu Concentration (mg/L) (Pu\} = Concentration of Pu on MST (mg/g) 
D. L. Fish

- page 15 -

WSRC-RP - 92-1273

Figure 5b. Tit of Uranium Loading Data to Iangmuir Adsorption Model

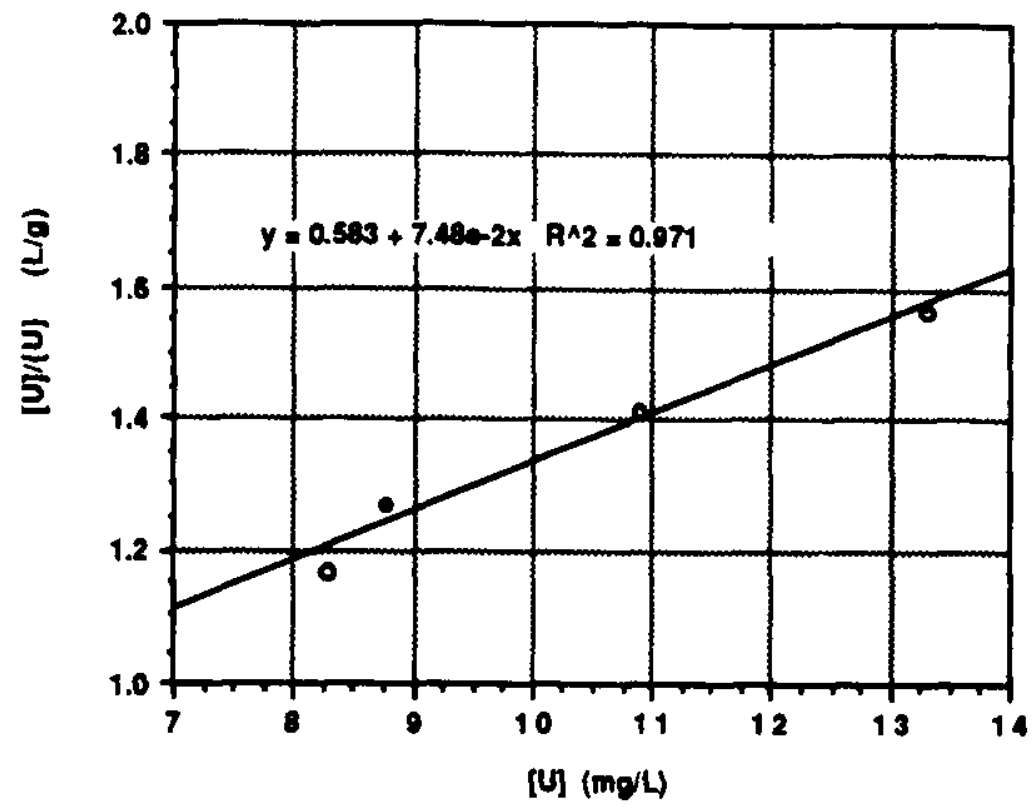

$[U]$ = Equillbrium Solution U Concentration (mq/L)

$\{U\}=$ Concentration of $U$ on MST (mg/g)

Figure 6a. Fit of Plutonim Ioading Data to Freundilich Adsorption Model

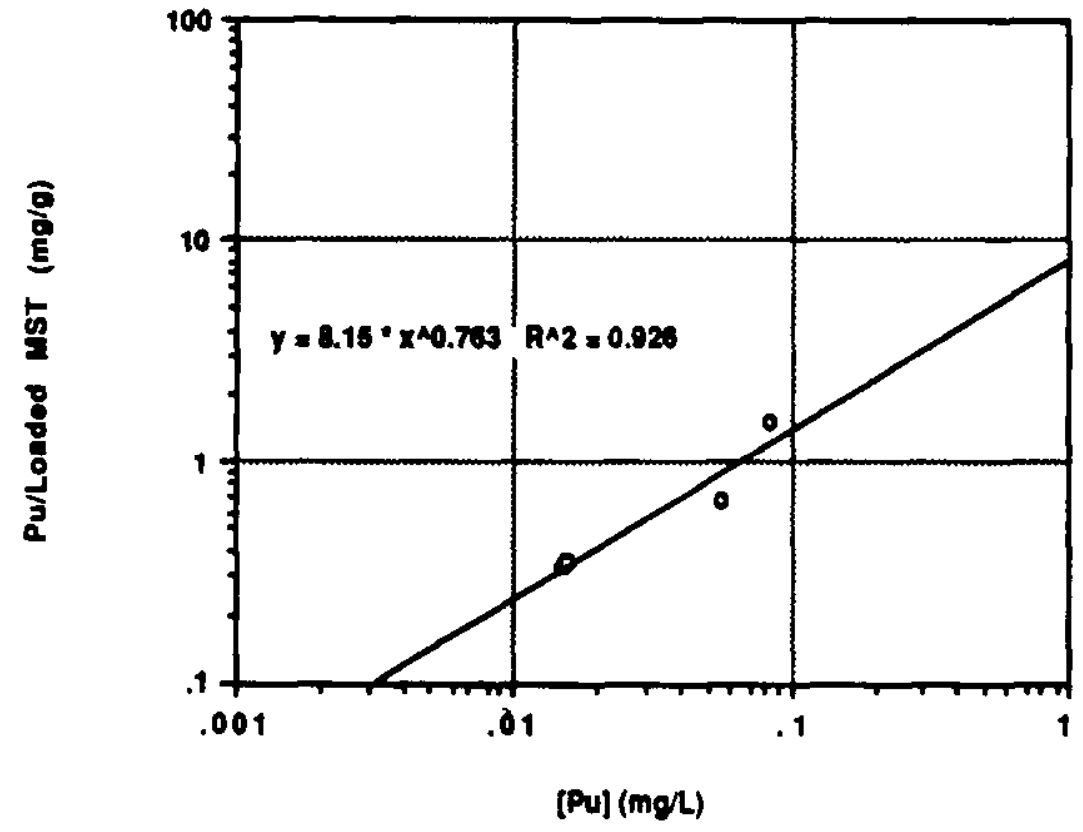


D. L. Fish

- page 16 -

WSRC-RP $-92-1273$

Figure 6b. Fit of Uranium Loading Data to Freundlich Adsorption Model

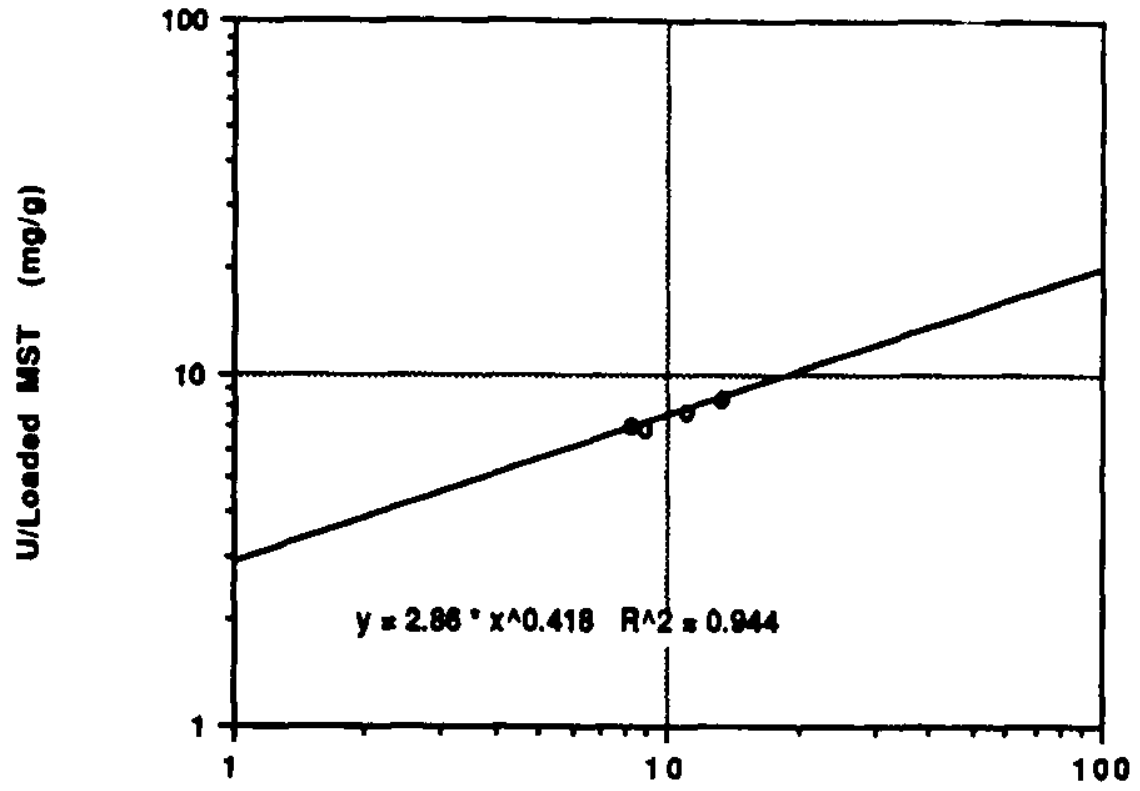

[U] (mgl)

Multiole-contact Batch Loading Test

During the ITP process, MST will be added during the first batch of a three-batch cycle. After a cycle is completed, a heel of slurry containing MST will be contacted with fresh salt solution prior to the addition of fresh MST. This operating plan thus provides for up to four contacts of a single batch of MST with fresh salt solution.

A four-contact batch loading test was conducted at ambient temperature to determine if the fissile loadings increase upon multiple contacts with salt solution saturated with plutonium and uranium. After four contacts of the MST at a concentration of 0.5 $\mathrm{g} / \mathrm{L}$, the fissile loadings were determined to be $0.12 \pm 0.0070$ wt. for plutonium and $1.5 \pm 0.083$ wt. for furanium. The plutonium loading is similar to that found previously in the single contact batch tests. The uranium loading is higher than that observed in the single contact batch tests.

\section{DISCUSSION}

\section{Solubility Tests}

Solubility tests were conducted with salt solutions containing the sodium salts of hydroxide, nitrate, nitrite, aluminate, sulfate and carbonate. The range of solution compositions was chosen to bound the range of compositions which will be treated in the ITP process. Over this range of solution compositions, the plutonium solubilities ranged from about 0.01 to $1.0 \mathrm{mg} / \mathrm{L}$. The range of 
solubilities observed in this study is consistent with that reported previously for similar salt solutions. Although there is a general trend to higher solubility with increased hydroxide concentration, there were no statistically significant factors or interactions affecting the solubility of plutonium over the tested range of salt compositions.

One factor, hydroxide concentration, and two interactions, hydroxide and nitrate and hydroxide and carbonate concentrations, were found to significantly affect the uranium solubility. The uranium solubility increases with an increase in the hydroxide concentration, but decreases with increases in either of the two interactions.

From 20 to $60^{\circ} \mathrm{C}$, which is the expected range of temperatures during salt dissolution, there appears to be no significant effect of temperature on either the plutonium solubility or the uranium solubility in alkaline salt solutions. From the test data, the maximum solubilities of plutonium and uranium in salt solutions which will be treated in the ITP process are approximately 1.0 $\mathrm{mg} / \mathrm{L}$ for plutonium and $15 \mathrm{mg} / \mathrm{L}$ for uranium.

\section{Leading Tests}

From the linear regression of the data and applying a correction factor of three times the relative error of duplicate tests, the maximum loading from salt solutions which will be treated in the ITP process at $19^{\circ} \mathrm{C}$ is determined to be 0.28 wt. 8 for plutonium and 1.1 wt. for uranium. These results are consistent with that previously determined indirectly from solution analyses at ambient laboratory temperatures. 5

Eigure 4 shows a plot of the plutonium and uranium loadings versus the MST concentration at $19^{\circ}$ and $72^{\circ} \mathrm{C}$ as determined by method $A$. Based on the loading results obtained at $72^{\circ} \mathrm{C}$ and a MST concentration of $0.102 \mathrm{~g} / \mathrm{L}$, plutonium loading increases with temperature and uranium loading decreases with temperature. The positive temperature effect for plutonium is the same behavior exhibited by strontium.9 The negative temperature effect for uranium suggests that uranium is removed from solution strictly by a surface adsorption process, since surface adsorption processes are known to exhibit an inverse temperature behavior. 10

Because of the questionable data quality for the high temperature tests conducted at a MST concentration of $0.50 \mathrm{~g} / \mathrm{L}$, a linear regression analysis of the plutonium loading data at $72^{\circ} \mathrm{C}$ was not performed. A graphical method was used to determine the maximum loading at $72^{\circ} \mathrm{C}$. From this analysis and applying the same correction factor for the relative error, a maximum loading of plutonium was determined to be 0.28 wt. 8 . This result is about $50 \%$ higher than the maximum loading determined at $19^{\circ} \mathrm{C}$. Over the expected temperature rarige bounding the ITP process $\left(40-70^{\circ} \mathrm{C}\right)$, the plutonium loading would be expected to vary by no more $30 \%$. 
Additional confirmatory tests are planned at the higher temperature to verify the effect of temperature on plutonium loading over the entire range of MST concentrations.

From the single-contact tests, the maximum loading of uranium from salt solutions which will be treated in the ITP process is determined to be $1.1 \mathrm{wt} . \mathrm{ot}^{\circ} 19^{\circ} \mathrm{C}$. In contrast to the behavior of plutonium and strontium, the uranium loading decreases with increasing temperature. From the available data, the uranium loading decreased by 30 upon a increase in temperature from $19^{\circ} \mathrm{C}$ to $72^{\circ} \mathrm{C}$. Over the expected temperature range bounding the ITP process $\left(40-70^{\circ} \mathrm{C}\right)$, the uranium loading would be expected to vary by no more 208 .

Strontium removal by MST has been reported to be a surface ion-exchange reaction. ${ }^{4}$ In an attempt to identify the removal mechanism for plutonium and uranium, the loading data were analyzed using several different models, including the same ion-exchange model for strontium as well as Langmuir and Freundich adsorption models.

The ion-exchange model was evaluated having the plutonium present in the salt solution as either the $\mathrm{PuO}_{2}{ }^{2+}$ or $\mathrm{PuO}_{2}{ }^{+}$species, and the uranium present as $\mathrm{UO}_{2}{ }^{2+}$ or $\mathrm{UO}_{2}{ }^{+}$species. The loading data showed no evidence of fitting the ion-exchange model with either of the two species being the predominate spectes in solution.

Fairly good fits to a Freundlich adsorption model were observed for the plutonium and uranium loading data obtained at $19^{\circ} \mathrm{C}$. Also, a fairly good fit to a Langmulr adsorption model was observed for the uranium loading data, but not for the plutonium loading data, obtained at $19^{\circ} \mathrm{C}$. These results indicate that the removal of uranium may strlctly be a surface adsorption mechanism, whereas the removal of plutonium may involve both surface adsorption and chemical reaction mechanisms. Additional pure component tests would be necessary to conclusively determine the removal mechanisms for each of the species.

From the Langmuir adsorption model analysis, the monolayer capacity of the MST for uranium was determined to be 1.3 wt. 8 . This loading is about twenty percent higher than the maximum value, 1.1 wt. 8 , determined from the single-contact batch loading tests at $19^{\circ} \mathrm{C}$, and about 15 lower than that found in the multiple-contact batch test. Because of the limited amount of data, it cannot be determined if the two single-contact loadings are statistically different.

The plutonium loading did not increase upon repeated contacts of the MST with salt solution saturated with plutonium. The uranium loading did increase upon multiple contacts. The slightly higher loading in the multiple-contact experiment compared to the monolayer capacity value may be due to the sorption/nucleation of uranium onto uranium-adsorbed sites of the MST resulting from the use of uranium-saturated salt solutions. 
Salt solutions which will be processed in the ITP process will not be at saturation since solutions produced by salt dissolution, which can be saturated, will be diluted from transfer operations (steam lifters) and the addition of dilution water to decrease the sodium ion concentration. Confirmatory multiple-contact batch loading experiments are planned at saturated and unsaturated uranium concentrations to verify the multiple-contact fissile loadings and the effects of uranium concentration.

For nuclear safety assessments of the ITP process, it is recommended that the following expressions for fissile loadings be used;

$$
\begin{aligned}
& \text { Wt. } 8 \mathrm{PU}=0.29-0.20 \mathrm{x} \\
& \text { Wt. } 8 \mathrm{U}=1.8-0.29 \mathrm{x} \\
& \text { where } \mathrm{x} \text { is the concentration of MST in } \mathrm{g} / \mathrm{L} \text {. }
\end{aligned}
$$

These expressions are valid over the range of MST concentrations from 0.05 to $0.51 \mathrm{~g} / \mathrm{L}$ and temperatures of $17^{\circ}-74^{\circ} \mathrm{C}$. The slopes for each of these equations were the smallest slopes determined from fitting the experimental loading data (see Figure 2). The $y$-intercept terms were determined by solving the expressions for the maximum loadings $(0.28$ wt. 8 Pu and 1.8 wt. 8 U) at a MST concentration of $0.05 \mathrm{~g} / \mathrm{L}$. The uranium expression is conservative since the above expression is based on the $19^{\circ} \mathrm{C}$ data, whereas the temperature of the slurry during ITP will range from about $40^{\circ}$ to $70^{\circ} \mathrm{C}$.

\section{Analysis of Experimental Errors}

Loadings determined by Method $B$ were consistently higher than those determined by Method A. Preliminary analyses of additional solubility data indicate that the analytical methods used to determine the concentrations of plutonium and uranium have similar accuracy and precision.11 The accuracy and the precision of the analytical methods for the determination of strontium and titanium are not known.

Experimental errors in the data reported in this document arise from the following sources; (1) analytical instruments,

(2) sampling and handling the MST slurry, (3) solution sampling and preparation for analyses, and (4) temperature variability. The total maximum error is estimated to be the sum of these errors and is estimated by comparing the results from the different instrumental methods for both the solubility tests and the batch loading tests. For the solubility test data, the total maximum error was determined to be $6.3 \%$ for the plutonium data and $5.4 \%$ for the uranium data. For the loading test data, the total maximum error was estimated by comparing the results of duplicate tests and the two different analytical methods. The maximum relative error based on these tests was 118 for both plutonium and uranium. 


\section{QUNIITY ASSURANCE}

All experimental work reported in this document was obtained in accordance with the requirements and controls established in the Task Technical Plan and the Task Quality Assurance Plan for this work.12-15 Experimental methods and data are recorded in laboratory notebooks WSRC-NB-91-151, WSRC-NB-92-181, WSRC-NB-92-195, WSRC-NB-92-324, and WSRC-NB-92-360.

\section{RIFHRERCES}

1. T. A. Reilley, "Nuclear Criticality Safety Analysis 88-3 Nuclear Criticality Safety of In-Tank Precipitations", DPSP-88-272-55, MaY 16, 1988.

2. Inter-office Memorandum from A. Q. Goslen to M. C. Chandler, "Nuclear Criticality Safety Analysis WM-92-I, Maximum Safe Loading of U-235 on Monosodium Dititanate, Rev. 1 (U),", WER-WME-920788, JulY 21, 1992.

3. Inter-office Memorandum from A. Q. Goslen and C. E. Bess to M. C. Chandler, "Nuclear Criticality Safety Analysis WM-92-2, Maximum Safe Masses of U-235 Loadings on Monosodium Dititanate, Rev. 1 (U),", WER-WME-920979, July 27, 1992.

4. W. W. Schultz, J. W. Koenst and D. R. Talent, "Application of Inorganic Sorbents in Actinide Separations Processes" in ACS Symposium Series 117, American Chemical Society, Washington, DC, 1980.

5. D. T. Hobbs and D. D. Walker, "Plutonium and Uranium Adsorption on Monosodium Titanate," WSRC-RP-92-93, August 13, 1992.

6. Inter-office Memorandum from J. H. Weber to D. T. Hobbs, "Fractional Eactorial Design," SCS-ASG-92037, May 6, 1992.

7. Inter-office Memorandum from T. B. Edwards to D. T. Hobbs, "Analysis of Fissile Solubility Test Data (U)," SCS-ASG-92048, July 6, 1992 .

8. C. H. Delegard, "Solubility of $\mathrm{PuO}_{2} \cdot \mathrm{xH}_{2} \mathrm{O}$ in Alkaline Hanford High-Level Waste Solution," Badiechimica Acta, 11. $11-21$ (1987).

9. D. T. Hobbs, "In-Tank Precipitation: Effect of Concentration, Temperature, and Reagent Addition Order on the Cesium-137 and Strontium-85 Decontamination Factors," DPST-85-420, April 9, 1985 .

10. S. D. Eaust and O. M. Aly, "Chemistry of Water Treatment," Butterworths, Boston, MA, 1983, page 290.

11. Personal communication-with T. B. Edwards, October 16, 1992. 
D. I. Fish

12. D. T. Hobbs, "Task Technical Plan for Eissile Solubility and Monosodium Titanate Loading Tests," WSRC-RP-92-574, Apri1 27, 1992.

13. D. T. Hobbs, "Addendum to Task Technical Plan for Eissile Solubility and Monosodium Titanate Loading Tests," WSRC-RP-92-574, Rev. 1, November 3, 1992.

14. D. T. Hobbs, "Task Quality Assurance Plan for Fissile Solubility and Monosodium Titanate Loading Tests," WSRC-RP $-92-575$.

15. Memo from D. T. Hobbs to D. L. Fish, "Use of Enriched Uranium in Fissile Solubility and Loading Tests," SRT-LWP-92-054, October 7, 1992 . 


\section{Approval sheet}

D. T. HObbs, WMEET/IWT

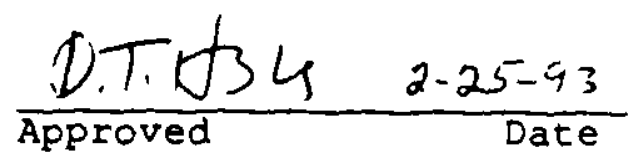

S. D. Fleischman, CPT

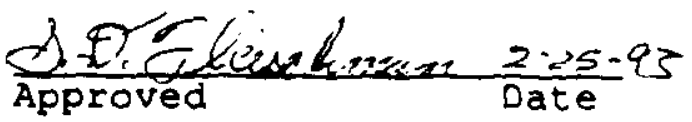

M. C. Chandler, WME

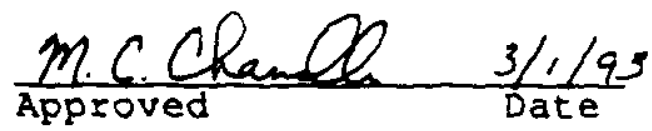

D. L. Fish, WM\&ET/IWT

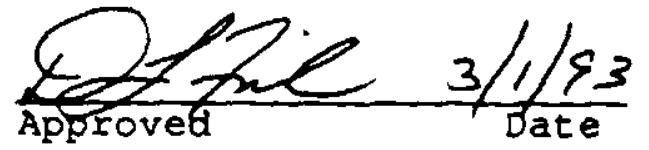

\section{Reviowed By:}

M. C. Thompson, CPT

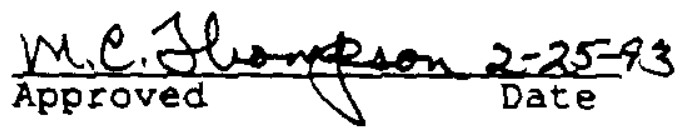

D. D. Walker, WM\&ET

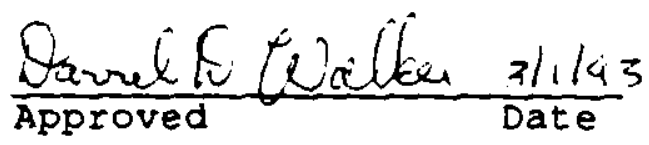

CC: T. M. Monahon, 703-H

B. L. Lewis, 703-H

W. A. Van Pelt, 241-121H

A. Q. Goslen, 773-22A

I. M. Papouchado, 773-A

W. L. Tamosaitis, 703-A

E. W. Holtzsche1ter, 773-A

M. C. Thompson, 773-A

W. S. Cavin, 773-A

J. R. Schornhorst, $992 \mathrm{~W}-1$

E. L. Wilhite, 773-43A

M. D. Boersma,

L. F. Landon, 704-T

IWT/LWE Eiles
R. A. Scaggs, 703- H
M. C. Chandler, 703-H
C. E. Bess, 703-H
D. A. Pervis, 241-152H
C. R. Wolfe, 773-A
A. I. Blancett, 773-A
M. J. Plodinec, 773-A
J. E. Marra, 703-K
M. K. Gupta, 992 W-1
T. S. Rudisill, 773-A
D. D. Walker, 773-A
M. S. Hay, 773-A
B. C. Ha, 773-A
SRTC Files (4) 
WESTINGHOUSE SAVANNAH RIVER COMPANY SAVANNAH RIVER IABORATORY
WSRC-RP $-92-1273$

Keywords :

Plutonium, Uranium, In-Tank Precipitation, High Level Waste, Strontium, Actinide, Criticality, Adsorption, Temperature

Retention time: permanent

February 12, 1993

TO: D. L. Eish, 773-A

DTH

FROM: D. T. Hobbs, 773-A and S. D. Eleischman, 773-A

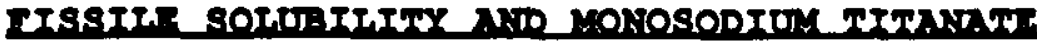

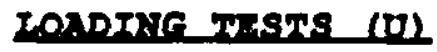

\section{SURARRY}

The solubilities of plutonium and uranium have been determined for alkaline salt solutions having compositions which bound those which will be processed in the In-Tank Precipitation (ITP) process. Loadings of plutonium and uranium onto monosodium titanate (MST) have been determined at temperatures bounding those expected to occur during ITP and using a salt solution which was determined to have the maximum solubility for uranium and plutonium. Fissile loadings increase with decreasing amounts of MST in contact with the salt solutions saturated in plutonium and uranium. At MST concentrations bounding those which are planned for the ITP process, expressions for the maximum loadings (wt. of) are determined to be 0.29 - $0.20 \times$ [MST] for plutonium and 1.8 $0.29 \times$ [MST] for urantum, where [MST] is the concentration of MST in grams/liter. These expressions are valid over the range of MST concentrations from 0.05 to $0.51 \mathrm{~g} / \mathrm{L}$ and temperatures of $17^{\circ}-74^{\circ} \mathrm{C}$. These loadings are below the individual infinitely safe limits for plutonium and uranium.1-3 Additional confirmatory experiments are planned to verify the effects of temperature and multiple contacts of the MST with fresh salt solution on the fissile loadings. 